This Section of Epidemiology and Psychiatric Sciences regularly appears in each issue of the Journal to describe relevant studies investigating the relationship between neurobiology and psychosocial psychiatry in major psychoses. The aim of these Editorials is to provide a better understanding of the neural basis of psychopathology and clinical features of these disorders, in order to raise new perspectives in every-day clinical practice.

Paolo Brambilla, Section Editor and Michele Tansella, Editor EPS

\title{
Interaction between cognition and emotion in developmental psychopathology: the role of linguistic stimuli
}

\author{
M. Bellani ${ }^{*}$, C. Bonivento ${ }^{3}$ and P. Brambilla ${ }^{2,3}$ \\ ${ }^{1}$ Department of Public Health and Community Medicine, Section of Psychiatry, Inter-University Center for Behavioural Neurosciences (ICBN), \\ University of Verona, Verona, Italy \\ ${ }^{2}$ Department of Experimental Clinical Medicine, Inter-University Center for Behavioural Neurosciences (ICBN), University of Udine, Udine, Italy \\ ${ }^{3}$ IRCCS "E. Medea" Scientific Institute, Udine, Italy
}

\begin{abstract}
Investigations on emotional words demonstrated that processing emotional information in child patients with anxiety disorders diagnosed for anxiety (generalized anxiety disorder and post-traumatic stress disorder) or depression is biased towards pathology-related stimuli. Also, neuroimaging studies showed a failure of prefrontal areas in inhibiting the emotional reaction in children with bipolar disorder. Finally, despite several studies investigated memory and attention using emotional words, little is known about the development of emotional lexicon in both healthy and psychopathological children.
\end{abstract}

Received 12 March 2012; Revised 14 March 2012; Accepted 17 March 2012; First published online 15 May 2012

Key words: Cognition, development, emotion, psychopathology.

The close interaction between emotion and cognition was suggested by behavioural and neuroimaging studies from both healthy and mentally ill individuals (e.g. Beck et al. 1979, 1985; Isen et al. 1987; Williams et al. 1997; Bush et al. 2000).

Cognitive processing of emotional material appears to be affected by pathology-coherent biases in individuals with emotional disorders (Beck et al. 1979, 1985; Bellani et al. 2011). Studies indicated that clinically depressed adults are keener on remembering negative/sad rather than positive material (e.g. Bradley et al. 1995), whereas anxious people show

*Address for correspondence: Dr. M. Bellani, Department of Public Health and Community Medicine, Section of Psychiatry and Clinical Psychology, University of Verona, Piazzale L.A. Scuro 10, 37134 Verona, Italy.

(Email: marcella.bellani@univr.it, paolo.brambilla@uniud.it) an attentional bias towards threatening stimuli (MacLeod et al. 1986). In addition, this bias seems to affect specific cognitive functions, but not others, in different psychiatric disorders. For instance, MacLeod et al. (1986) tested general anxiety disorder (GAD) and depressed adults with an emotional dot-probe detection task. The task consisted in detecting a dot that could appear in the same or different location as either an emotional threat-related or neutral word. They showed an attentional bias towards threat-related stimuli, if compared with the neutral condition, only in GAD (i.e. faster detection when the dot appeared in the same location as the threat-related word). The depressed patients, instead, attended equally to the emotional and neutral words (MacLeod et al. 1986). A lack of effect of negative emotional stimuli in depressed adults was confirmed in another study that used the same dot-probe 
detection task, but presented depression-related, instead of threat-related words (Gotlib et al. 1988). Conversely, an emotional symptom-congruent bias was found only in clinically depressed but not in GAD adults by Bradley et al. (1995). They showed that depressed patients freely recalled more depression-relevant than anxiety-relevant or neutral word and were faster in a lexical decision task when they had to answer to previously primed depression-relevant words.

Neuroimaging investigations in healthy volunteers suggested a parcellation of the anterior cingulate cortex (ACC) into a cognitive and emotional part that interacts through a mechanism of reciprocal suppression. In particular, cognitive demanding tasks activate the cognitive ACC part as well as a deactivation of the emotional ACC part. Conversely, emotional stimulation leads to activation of the emotional ACC and deactivation of the cognitive ACC part (see Bush et al. 2000 for review). In addition, a reduced activation in left ventral prefrontal cortex (PFC) was found in adults with bipolar disorder (BD) when performing an emotional-modified Stroop colour-naming task requiring to say the colour on which a word was written while ignoring the word itself - if compared with controls (Malhi et al. 2005).

A pattern of cognitive biases similar to the one found in adults was revealed in children with emotional disorders. For instance, clinically depressed children recalled significantly more negative (e.g. sad) adjectives than (e.g. happy) positive, whereas the controls had comparable performances with both. Interestingly, this tendency became stronger with age in the depressed group. In addition, the same study did not find any difference between the depressed and the control groups in a recognition task (Neshat-Doost et al. 1998). This suggested that, similarly to adults, in paediatric depression the bias is specific to one cognitive domain, as it acts only on free later recall and not on delayed recognition of previously presented emotional material.

This result (i.e. symptom-congruent memory bias) was not replicated in a study that tested children and adolescents with depression, GAD or post traumatic stress disorder (PTSD) (Dalgleish et al. 2003), probably because other-referent words (e.g. sadness) and not self-referent adjectives (e.g. sad) were used. Beside memory, Dalgleish et al. (2003) highlighted an attention bias towards threatening stimuli specific to the anxious group (GAD and PTSD combined together), with anxious detecting faster the dot-probe when presented in the same location as a threat related word (e. g. horror). However, only the GAD showed a bias towards threat-related words, whereas PTSD had a bias away from depression-related words (i.e. they were slower in detecting the dot-probe when it appeared in the same location as the depression related word). Depressed and control children did not show any symptom-congruent attentional bias and no group reported any effect in the modified Stroop task. These results are consistent with previous investigations in both adults (Beck et al. 1979, 1985; also see Williams et al. 1997 for a review) and children (Taghavi et al. 1999; Bot et al. 2011) and favour the hypothesis that a symptom-congruent bias on attention is specific to anxiety disorder.

An attention bias towards words expressing socialtreat and manic/irritable mood was reported on a sample of children of BD parents on an emotional Stroop task administered after negative mood induction (Gotlib et al. 2005). Also, in a functional magnetic resonance imaging (fMRI) study, negative words, relative to the neutral, elicited greater activation in the ACC and left amygdala and less activation in right rostral ventrolateral PFC and dorsolateral PFC in BD children. This favours the hypothesis that in paediatric BD there is both an enhanced reactivity in the limbic system and a reduced capacity of regulating this response by PFC when negative emotional stimuli are presented. The same pattern of activation was not found in paediatric BD for the positive words and it was not present for the healthy controls, neither in the positive condition nor in the negative condition (Pavuluri et al. 2008).

In summary (Table 1), cognitive functions seem to be biased in paediatric psychopathology in a way that mirrors the pattern of biases previously found in adults. The bias was revealed to be symptom-coherent and the cognitive functions involved appear to depend on the specific disorder that is taken into account. Moreover, the same neural substrates that proved to process or regulate emotional states in adults were found to have an atypical pattern of activation in children with anxiety disorders or BD. Indeed, the biases on cognitive functions are established in the early life, supported by an unusual development in some aspects of the neural substrates functionality, and more specifically in the ACC, in the limbic system and in the PFC, and are maintained throughout adulthood.

More research is needed to better define which cognitive functions suffer from emotional biases in different disorders, as well as the mechanisms through which those biases act. Moreover, despite the wide use of emotional linguistic stimuli in research on psychopathology, to date no studies investigated the development of the emotional as compared with neutral word lexicon in children with emotional disorders. Hence, we suggest that investigations on emotional 
Table 1. Summary of the results

\begin{tabular}{|c|c|c|c|c|c|}
\hline Study & Subjects & $\begin{array}{l}\text { Subjects mean age } \\
\text { (years) }\end{array}$ & Type of study & Tasks administered & Main findings \\
\hline \multirow[t]{3}{*}{ MacLeod et al. (1986) } & 16 GAD & 32.1 & \multirow[t]{3}{*}{ Behavioural } & \multirow[t]{3}{*}{ 'Emotional' dot-probe detection task } & \multirow{3}{*}{$\begin{array}{l}\text { GAD only had an attentional bias } \\
\text { towards threat-related words }\end{array}$} \\
\hline & 16 depressed adults & 43.0 & & & \\
\hline & 16 healthy adults & 36.9 & & & \\
\hline Isen et al. (1987) & 278 students & Not available & Behavioural & $\begin{array}{l}\text { Candle task } \\
\text { Remote Associates Test }\end{array}$ & $\begin{array}{l}\text { Induced positive affect improves } \\
\text { creative problem-solving } \\
\text { performance }\end{array}$ \\
\hline \multirow[t]{2}{*}{ Gotlib et al. (1988) } & 12 depressed adults & 19 & \multirow[t]{2}{*}{ Behavioural } & \multirow[t]{2}{*}{ 'Emotional' dot-probe detection task } & \multirow{2}{*}{$\begin{array}{l}\text { Depressed adults did not show an } \\
\text { attentional bias towards } \\
\text { depression-related words }\end{array}$} \\
\hline & 12 healthy controls & 19 & & & \\
\hline \multirow[t]{4}{*}{ Bradley et al. (1995) } & 17 GAD & 38.1 & \multirow[t]{4}{*}{ Behavioural } & \multirow{4}{*}{$\begin{array}{l}\text { Explicit memory: free recall of previously } \\
\text { presented depression- or } \\
\text { anxiety-relevant and neutral words. } \\
\text { Implicit memory: lexical decision } \\
\text { between real and unreal words using } \\
\text { depression- or anxiety-relevant and } \\
\text { neutral stimuli }\end{array}$} & \multirow{4}{*}{$\begin{array}{l}\text { Only depressed showed a memory } \\
\text { bias in favour of } \\
\text { symptoms-congruent stimuli } \\
\text { both in the explicit and implicit } \\
\text { memory tasks }\end{array}$} \\
\hline & 19 depressed adults & 33.3 & & & \\
\hline & 18 healthy adults & 39.6 & & & \\
\hline & & & & & \\
\hline \multirow{2}{*}{$\begin{array}{l}\text { Neshat-Doost et al. } \\
\text { (1998) }\end{array}$} & 19 depressed children & 15.43 & \multirow[t]{2}{*}{ Behavioural } & \multirow[b]{2}{*}{$\begin{array}{l}\text { Free recall for affective positive and } \\
\text { negative and neutral words } \\
\text { Delayed recognition of previously } \\
\text { presented affective positive and } \\
\text { negative and neutral words }\end{array}$} & \multirow{2}{*}{$\begin{array}{l}\text { Depressed only had a bias towards } \\
\text { negative affective words only in } \\
\text { the free recall condition }\end{array}$} \\
\hline & 19 healthy children & 15.35 & & & \\
\hline \multirow[t]{4}{*}{ Taghavi et al. (1999) } & 24 GAD children & 13.56 & \multirow[t]{4}{*}{ Behavioural } & \multirow[t]{4}{*}{ 'Emotional' dot-probe detection task } & \multirow{4}{*}{$\begin{array}{l}\text { GAD only had an attentional bias } \\
\text { towards threat-related stimuli } \\
\text { No other biases were } \\
\text { highlighted in any group }\end{array}$} \\
\hline & 19 anxiety-depressive disorder & 14.84 & & & \\
\hline & children & 13.18 & & & \\
\hline & 24 healthy children & & & & \\
\hline \multirow[t]{4}{*}{ Dalgleish et al. (2003) } & 24 GAD children & 13.57 & \multirow[t]{4}{*}{ Behavioural } & \multirow{4}{*}{$\begin{array}{l}\text { 'Emotional' dot-probe detection task and } \\
\text { emotional-modified Stroop task }\end{array}$} & \multirow{4}{*}{$\begin{array}{l}\text { GAD and PTSD only had } \\
\text { attentional bias towards } \\
\text { symptom-congruent stimuli in } \\
\text { the dot-probe detection }\end{array}$} \\
\hline & 24 PTSD children & 12.83 & & & \\
\hline & 19 depressed children & 15.58 & & & \\
\hline & 24 healthy children & 15.15 & & & \\
\hline Gotlib et al. (2005) & $\begin{array}{l}16 \text { children of } \mathrm{BP} \\
10 \text { children of not } \mathrm{BP}\end{array}$ & Age range 9-14 & Behavioural & $\begin{array}{l}\text { Emotional-modified Stroop task } \\
\text { administered after negative mood } \\
\text { induction }\end{array}$ & $\begin{array}{l}\text { Only BP offspring children had an } \\
\text { emotional bias towards } \\
\text { emotional negative words } \\
\text { (social-treat and manic-irritable } \\
\text { mood) }\end{array}$ \\
\hline
\end{tabular}


language should be carried out to have clearer pictures of each psychopathology and to plan effective therapeutic strategies.

\section{References}

Beck AT, Emery G, Greenberg RL (1985). Anxiety Disorders and Phobias: A Cognitive Perspective. Basic Books: New York.

Beck AT, Rush AJ, Shaw BF, Emery G (1979). Cognitive Therapy of Depression: A Treatment Manual. Guilford: New York.

Bellani M, Moretti A, Perlini C, Brambilla P (2011). Language disturbances in ADHD. Epidemiology and Psychiatric Sciences 20, 311-315.

Bot M, de Leeuw den Bouter BJ, Adriaanse MC (2011). Prevalence of psychosocial problems in Dutch children aged 8-12 years and its association with risk factors and quality of life. Epidemiology and Psychiatric Sciences 20, 357-365.

Bradley B, Mogg K, Williams R (1995). Implicit and explicit memory for emotion-congruent information in clinical depression and anxiety. Behavioural Research and Therapy 33, 755-770.

Bush G, Luu P, Posner MI (2000). Cognitive and emotional influences in anterior cingulate cortex. Trends in Cognitive Sciences 4, 215-222.

Dalgleish T, Taghavi R, Neshat-Doost H, Moradi A, Canterbury R, Yule W (2003). Patterns of processing bias for emotional information across clinical disorders: a comparison of attention, memory, and prospective cognition in children and adolescents with depression, generalised anxiety and posttraumatic stress disorder. Journal of Clinical Child and Adolescent Psychology 32, 10-21.

Gotlib IH, McLachlan AI, Katz AN (1988). Biases in visual attention in depressed and nondepressed individuals. Cognition and Emotion 2, 185-200.

Gotlib IH, Traill SK, Montoya RL, Joormann J, Chang K (2005). Attention and memory biases in the offspring of parents with bipolar disorder: indications from a pilot study. Journal of Child Psychology and Psychiatry 46, 84-93.

Isen AM, Daubman KA, Nowicki GP (1987). Positive affect facilitates creative problem solving. Journal of Personality and Social Psychology 52, 1122-1131.

MacLeod C, Mathews A, Tata P (1986). Attentional bias in emotional disorders. Journal of Abnormal Psychology 95, 15-20.

Malhi GS, Lagopoulos J, Sachdev PS, Ivanovski B, Shnier R (2005). An emotional Stroop functional MRI study of euthymic bipolar disorder. Bipolar Disorder 7, 58-69.

Neshat-Doost H, Taghavi R, Moradi A, Yule W, Dalgleish T (1998). Memory for emotional trait adjectives in clinically depressed youth. Journal of Abnormal Psychology 107, 642-650.

Pavuluri MN, O'Connor MM, Harral EM, Sweeney JA (2008). An fMRI study of the interface between affective 
and cognitive neural circuitry in paediatric bipolar disorder. Psychiatry Research 162, 244-255.

Taghavi R, Neshat-Doost H, Moradi A, Yule W, Dalgleish T (1999). Biases in visual attention in children and adolescents with clinical anxiety and mixed-anxiety- depression. Journal of Abnormal Child Psychology 27, 215-223.

Williams JMG, Watts FN, MacLeod C, Mathews A (1997). Cognitive Psychology and Emotional Disorders, 2nd edn. Wiley: Chichester, England. 